\title{
Meta-analysis of the Effect of Shenfu Injection on Immune Function in Patients with Sepsis
}

\author{
Yuanli He' ${ }^{1}$ Jiawen Zhang1, Yang Shi', Meng Li ${ }^{2 *}$ \\ ${ }^{1}$ Shaanxi University of Chinese Medicine, Xianyang 712046, Shaanxi Province, China \\ ${ }^{2}$ Shaanxi Provincial Hospital of Chinese Medicine, Xi'an 710003, Shaanxi Province, China \\ *Corresponding author: Meng Li, zmwq7812@sina.com
}

\begin{abstract}
Objective: To systematically evaluate the effects of Shenfu Injection on immune function of sepsis patients by meta-analysis. Methods: The randomized controlled trials of Shenfu Injection in the treatment of sepsis published from 2000 to February 2021 were searched in CNKI, WanFang database and VIP database. The control group was treated with routine treatment; The experimental group was treated with Shenfu Injection on the basis of routine treatment. The included literature was evaluated by Cochrane bias risk evaluation table, and Shenfu Injection was used to treat patients with sepsis with RevMan 5.3 software. The results of meta-analysis were as reported. Conclusion: However, due to the limitation of the quality and quantity of the included research, multi center, large sample volume and high-quality RCT are still needed to verify the research results.
\end{abstract}

Keywords: Shenfu Injection; Sepsis; Curative effect; Meta-analysis

Publication date: November 2021; Online publication: November 30, 2021

\section{Introduction}

Immunosuppression secondary to immune dysfunction is the main pathogenesis of sepsis. Immune related therapy has become the focus of sepsis treatment research and a new opportunity for sepsis treatment with traditional Chinese medicine ${ }^{[1]}$.

Pharmacological studies of Shenfu Injection show that it can balance immune disorder, reduce endotoxin and immune inflammatory response, but its effect on immune function and immune inflammatory response in patients with sepsis remains to be confirmed by clinical research. It is necessary to observe the effect of Shenfu Injection on immune function in patients with sepsis and explore its application value in immune regulation.

\section{Materials and methods}

\subsection{Inclusion criteria}

Research types were, randomized controlled trial (RCT) was conducted in Chinese and English, with no restriction on allocation concealment and blinding methods. The selected subjects were patients with definite diagnosis of sepsis. Interventions The control group received routine treatment, mainly including fluid resuscitation, anti-infection, anticoagulation, administration of vasoactive drugs and glucocorticoids. The experimental group (Shenfu group) added Shenfu Injection on the basis of the control group, and the administration methods were intravenous injection, intravenous drip or intramuscular injection. Outcome measures were (1) the level of CD3+; (2) the level of CD4+; (3) the level of CD8+; (4) the levels of CD4+ / CD8+; (5) Percentage of natural killer (NK) cells; (6) Efficiency; (7) Mortality. 


\subsection{Exclusion criteria}

Animal experiments, summary studies, etc. The outcome indicators were inconsistent with the text description. Re published research or research with missing data or unable to obtain the full text; Studies with unclear course of treatment.

\subsection{Literature search}

Two researchers independently searched the RCTs of Shenfu Injection in the treatment of sepsis patients in CNKI, WanFang Data, VIP database and PubMed before February 1, 2021. Chinese key words include "Shenfu Injection," "septicopyemia," "sepsis" and "severe sepsis." Different key words were matched and searched respectively, and screened according to the inclusion criteria.

\subsection{Data extraction}

Two researchers completed data extraction independently. In case of differences, they settled their differences through negotiation or by asking a third party. The extracted data mainly include the basic information, intervention measures, course of treatment and outcome indicators.

\subsection{Quality evaluation}

Referring to the Cochrane bias risk assessment tool, the quality of the included studies was evaluated, including the generation of random allocation scheme, allocation concealment, blinding implementation, selective reporting results, data integrity and other bias sources. High risk of bias indicated that the implementation method was wrong, low risk of bias indicated that it was correct, and unclear risk of bias indicated that there was a lack of description of this part ${ }^{[2]}$.

\subsection{Data analysis}

The data were meta-analyzed by Review Manger 5.3 software. The measurement data and count data were expressed by mean difference (MD), relative risk (RR) and 95\% confidential intervals (95\% CI) respectively. $\chi^{2}$ test was carried out first. When $\mathrm{P}>0.10$ and $\mathrm{I}^{2} \leq 50 \%$, heterogeneity was not obvious, and fixed effect model was used. When $\mathrm{P} \leq 0.10$ and $\mathrm{I}^{2}>50 \%$, the random-effect model was used, and the inverted funnel plot was used to test the publication bias.

\section{Results}

\subsection{Literature screening results}

There were 373 relevant literatures obtained through preliminary examination. After screening, 6 were finally included, all of which were in Chinese. The screening process and results of included literatures were shown in Figure 1. 6 articles used random number table, and 1 article did not clearly give the grouping method; All included studies were not lost to follow-up, and did not mention blinding method, allocation concealment and intention analysis. See Figure 2.

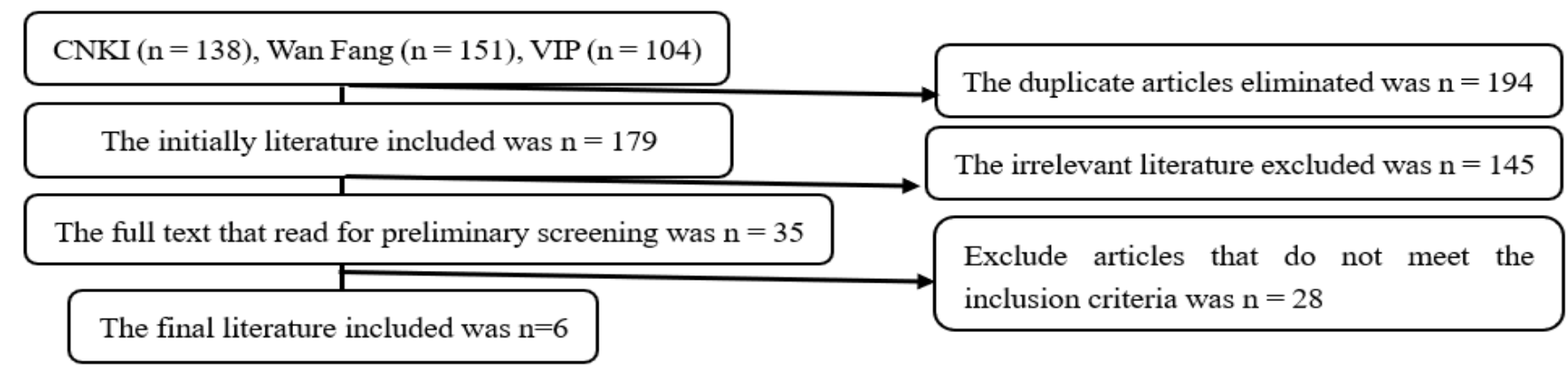

Figure 1. The screening process and results of included literatures 


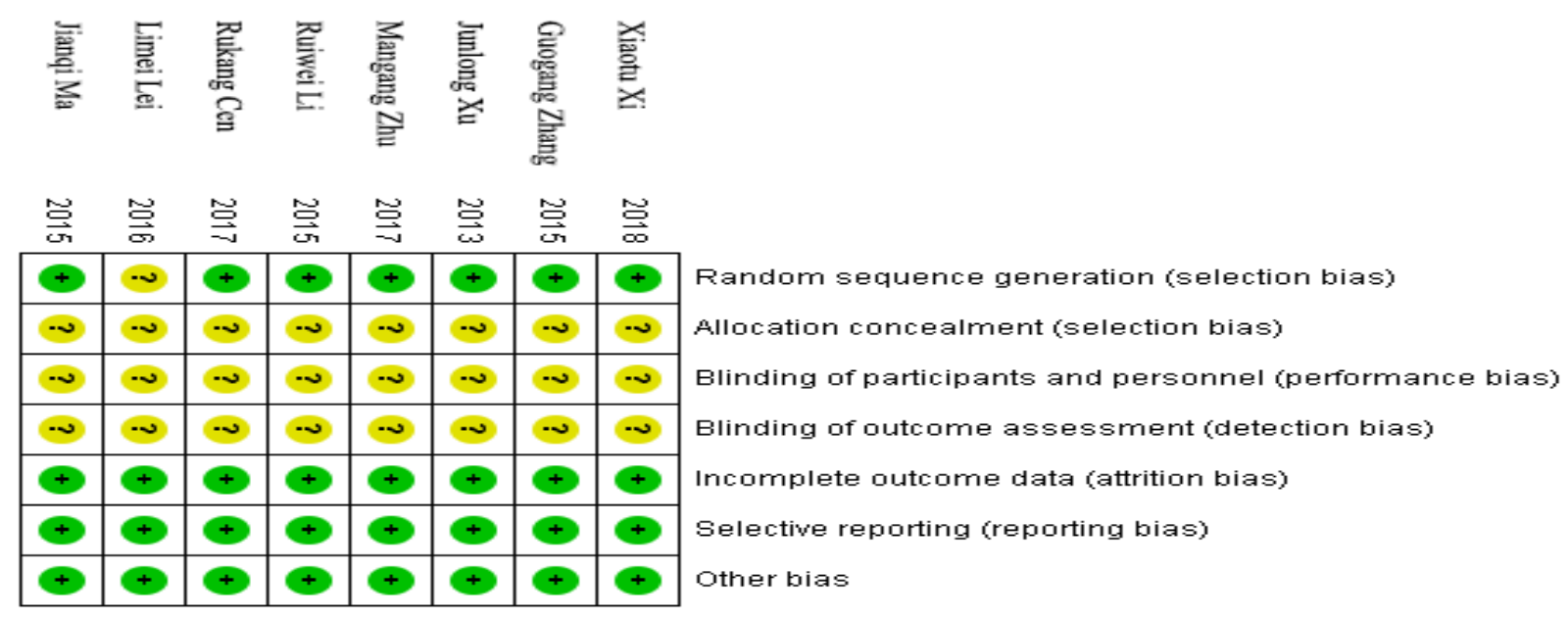

Figure 2. Bias of included literature

\subsection{Basic characteristics of the included study}

Table 1. Characteristics of the included study

\begin{tabular}{|c|c|c|c|c|c|c|c|c|}
\hline \multirow{2}{*}{$\begin{array}{l}\text { Inclusion } \\
\text { study }\end{array}$} & \multirow{2}{*}{ Year } & \multirow{2}{*}{$\begin{array}{l}\text { Grouping } \\
\text { method }\end{array}$} & \multirow{2}{*}{$\begin{array}{c}\text { Number } \\
\text { of cases } \\
(\mathrm{T} / \mathrm{C})\end{array}$} & \multirow{2}{*}{$\begin{array}{l}\text { Average age } \\
\mathrm{T} / \mathrm{C} \text { years }\end{array}$} & \multicolumn{2}{|c|}{ Interventions } & \multirow{2}{*}{$\begin{array}{c}\text { Course of } \\
\text { treatment } \\
\text { / day }\end{array}$} & \multirow{2}{*}{$\begin{array}{l}\text { Outcome } \\
\text { indicators }\end{array}$} \\
\hline & & & & & $\mathrm{T}$ & $\mathrm{C}$ & & \\
\hline $\begin{array}{l}\text { Limei } \\
\text { Lei }^{[3]}\end{array}$ & 2015 & Unknown & $30 / 30$ & $\begin{array}{l}\mathrm{T}(31.7 \pm 7.2) \\
\mathrm{C}(32.7 \pm 8.1)\end{array}$ & $\begin{array}{l}\text { Shenfu Injection + } \\
\text { conventional } \\
\text { therapy }\end{array}$ & $\begin{array}{l}\text { Conventional } \\
\text { therapy }\end{array}$ & $7 d$ & $\begin{array}{c}\text { (1) } 2 \text { (3) } \\
\text { (5) } 6\end{array}$ \\
\hline $\begin{array}{l}\text { Jianqi } \\
\mathbf{M a}^{[4]}\end{array}$ & 2015 & $\begin{array}{l}\text { Random } \\
\text { number } \\
\text { table }\end{array}$ & $60 / 60$ & $\begin{array}{l}\mathrm{T}(51.3 \pm 4.3) \\
\mathrm{C}(49.3 \pm 5.3)\end{array}$ & $\begin{array}{l}\text { Shenfu Injection + } \\
\text { conventional } \\
\text { therapy }\end{array}$ & $\begin{array}{l}\text { Conventional } \\
\text { therapy }+ \\
\text { Ulinastatin }\end{array}$ & $7 d$ & (1) (2) (4) \\
\hline $\begin{array}{c}\text { Junlong } \\
\text { Xu }^{[5]}\end{array}$ & 2013 & $\begin{array}{l}\text { Random } \\
\text { number } \\
\text { table }\end{array}$ & $36 / 32$ & $\begin{array}{l}\mathrm{T}(49.3 \pm 15.5) \\
\mathrm{C}(50.5 \pm 17.2)\end{array}$ & $\begin{array}{l}\text { Shenfu Injection + } \\
\text { conventional } \\
\text { therapy }\end{array}$ & $\begin{array}{l}\text { Conventional } \\
\text { therapy }\end{array}$ & $7 d$ & (1) (2) (3) \\
\hline $\begin{array}{c}\text { Ruiwei } \\
\text { Li }^{[6]}\end{array}$ & 2015 & $\begin{array}{l}\text { Random } \\
\text { number } \\
\text { table }\end{array}$ & $33 / 32$ & $\begin{array}{l}\mathrm{T}(49.3 \pm 15.5) \\
\mathrm{C}(50.5 \pm 17.2)\end{array}$ & $\begin{array}{l}\text { Shenfu Injection + } \\
\text { low dose } \\
\text { hydrocortisone + } \\
\text { conventional } \\
\text { therapy }\end{array}$ & $\begin{array}{l}\text { Conventional } \\
\text { therapy }\end{array}$ & $7 d$ & $\begin{array}{c}\text { (2) } 36 \\
\text { (7) }\end{array}$ \\
\hline $\begin{array}{l}\text { Guogang } \\
\text { Zhang }{ }^{[7]}\end{array}$ & 2015 & $\begin{array}{l}\text { Random } \\
\text { number } \\
\text { table }\end{array}$ & $30 / 30$ & $\begin{array}{c}\mathrm{T} \\
(50.50 \pm 17.20) \\
\mathrm{C} \\
(50.50 \pm 17.25)\end{array}$ & $\begin{array}{l}\text { Shenfu Injection + } \\
\text { conventional } \\
\text { therapy }\end{array}$ & Routine & $7 d$ & $\begin{array}{l}\text { (2) } 3 \\
56\end{array}$ \\
\hline $\begin{array}{c}\text { Xiaotu } \\
\mathbf{X i}^{[8]}\end{array}$ & 2018 & $\begin{array}{l}\text { Random } \\
\text { number } \\
\text { table }\end{array}$ & $21 / 21$ & $\begin{array}{c}\mathrm{T} \\
(72.63 \pm 10.25) \\
\mathrm{C} \\
(77.85 \pm 15.31)\end{array}$ & $\begin{array}{l}\text { Shenfu Injection + } \\
\text { conventional } \\
\text { therapy }\end{array}$ & Routine & $7 d$ & (4) 7 \\
\hline
\end{tabular}

Note: (1) the level of CD3+; (2) the level of CD4+; (3) the level of CD8+; (4) the levels of CD4+ / CD8+; (5) Percentage of natural killer (NK) cells; (6) Efficiency; (7) Mortality

A total of 6 RCT studies were included, all of which were Chinese literature. The publication period ranged from 2013 to 2018 . The minimum sample size was 42 cases, the maximum sample size was 120 cases. A 
total of 415 patients were enrolled, including 210 in experimental group and 205 in control group. All studies described in detail the treatment methods, course of treatment and outcome indicators of the experimental group and the control group. See Table 1 for details.

\subsection{Efficiency}

Two of the included articles made statistics on the outcome index of effective rate, which totally was 109 cases, including 63 cases in experimental group and 62 cases in control group, and 60 cases and 49 cases in effective population, respectively. Meta-analysis took OR as the effect quantity, and conducted Q-test on the heterogeneity. It was found that the heterogeneity between the effect quantities $\left(\mathrm{I}^{2}=0 \%, \mathrm{P}=0.71\right)$, indicating that there was no heterogeneity among the studies, that is, the homogeneity was relatively good, so the fixed effect model M-H method was used for analysis. The meta-analysis results were as follows: The effect value $\mathrm{OR}=5.34,95 \% \mathrm{CI}(1.43,19.85) \mathrm{Z}=2.50, \mathrm{P}=0.01$, that is, the effective rate of the experimental group (95.24\%) was significantly higher than that of the control group (79.03\%), and the difference between the two groups was statistically significant $(\mathrm{P}<0.05)$. As shown in Figure 3:

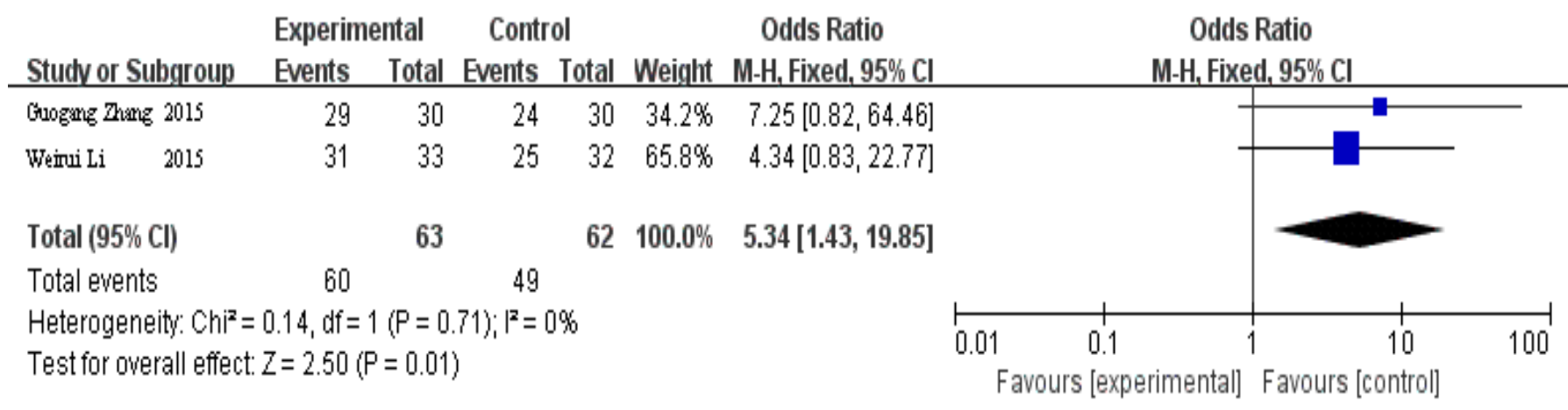

Figure 3. Efficient forest map

\subsection{Mortality}

Four included articles made statistics on the outcome index of mortality, which totally was 287 cases, including 144 cases in the experimental group and 143 cases in the control group, and the number of deaths were 19 cases and 41 cases respectively. Meta-analysis took OR as the effect quantity, and conducted Qtest on the heterogeneity. It was found that the heterogeneity between the effect quantities $\left(\mathrm{I}^{2}=0 \%, \mathrm{P}=\right.$ 0.83 ), indicating that there was no heterogeneity among the studies, that is, the homogeneity was relatively good, so the fixed effect model M-H method was used for analysis. The meta-analysis results were as follows: The effect value $\mathrm{OR}=0.37,95 \% \mathrm{CI}(0.20,0.68) \mathrm{Z}=3.19, \mathrm{P}=0.001$, that is, the mortality of the experimental group (13.19\%) was significantly lower than that of the control group (28.67\%), and the difference between the two groups was statistically significant $(\mathrm{P}<0.05)$. As shown in Figure 4:

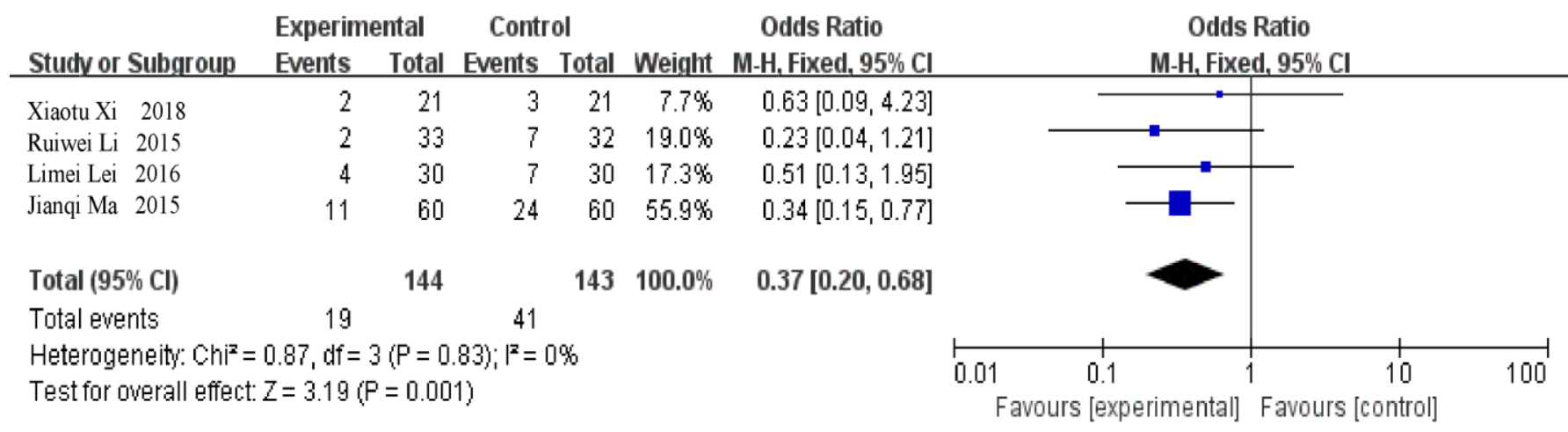

Figure 4. Mortality forest map 


\subsection{CD3+}

Three of the included articles made statistics on the outcome index of CD3 +, which totally was 248 cases, including 126 cases in the experimental group and 122 cases in the control group. Meta-analysis took SMD as the effect quantity, and conducted Q-test on the heterogeneity. It was found that the heterogeneity between the effect quantities $\left(\mathrm{I}^{2}=0 \%, \mathrm{P}=0.71\right)$, indicating that there was no heterogeneity among the studies, so the fixed effect model M-H method was used for analysis. The results of Meta-analysis were: The effect value SMD $=1.82,95 \% \mathrm{CI}(-0.05,0.45) \mathrm{Z}=1.58, \mathrm{P}=0.11$, that is, although there was a difference in $\mathrm{CD} 3$ + between the experimental group and the control group, the difference between the two groups was not statistically significant $(\mathrm{P}>0.05)$. As shown in Figure 5:

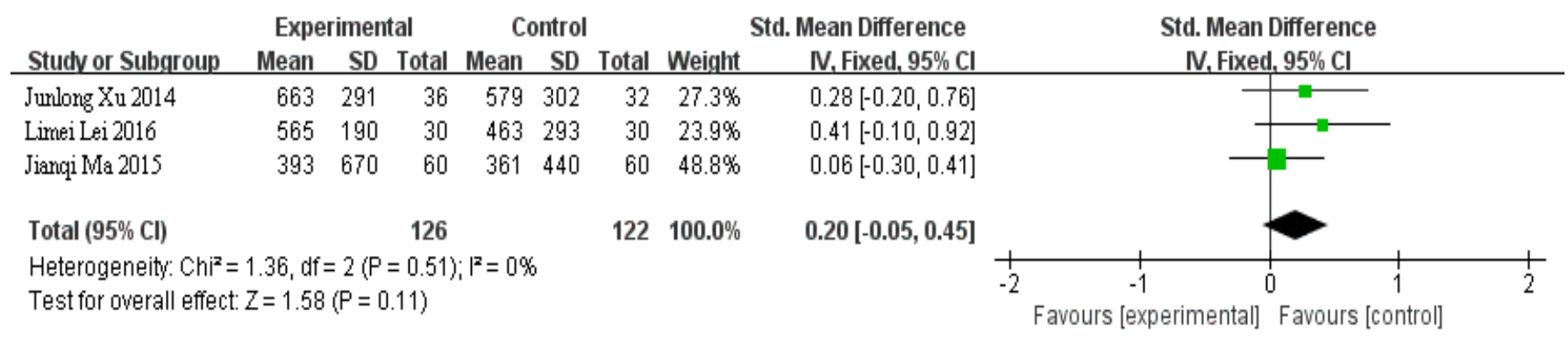

Figure 5. CD3 + forest map

\subsection{CD4+}

Six articles made statistics on the outcome index of CD4 +, which totally was 410 cases, including 207 cases in the experimental group and 203 cases in the control group. In meta-analysis, SMD was used as the effect quantity, and Q-test was conducted for heterogeneity. It was found that there was no heterogeneity among the effects $\left(\mathrm{I}^{2}=0 \%, \mathrm{P}=0.50\right)$, indicating that there was no heterogeneity among the studies, so the fixed effect model M-H method was used for analysis. The results of Meta-analysis were: The effect value $\mathrm{SMD}=0.22,95 \% \mathrm{CI}(0.02,0.41) \mathrm{Z}=2.18, \mathrm{P}=0.03$, that is, although there was a difference in CD4 + between the experimental group and the control group, the difference between the two groups was statistically significant $(\mathrm{P}<0.05)$. As shown in Figure 6:

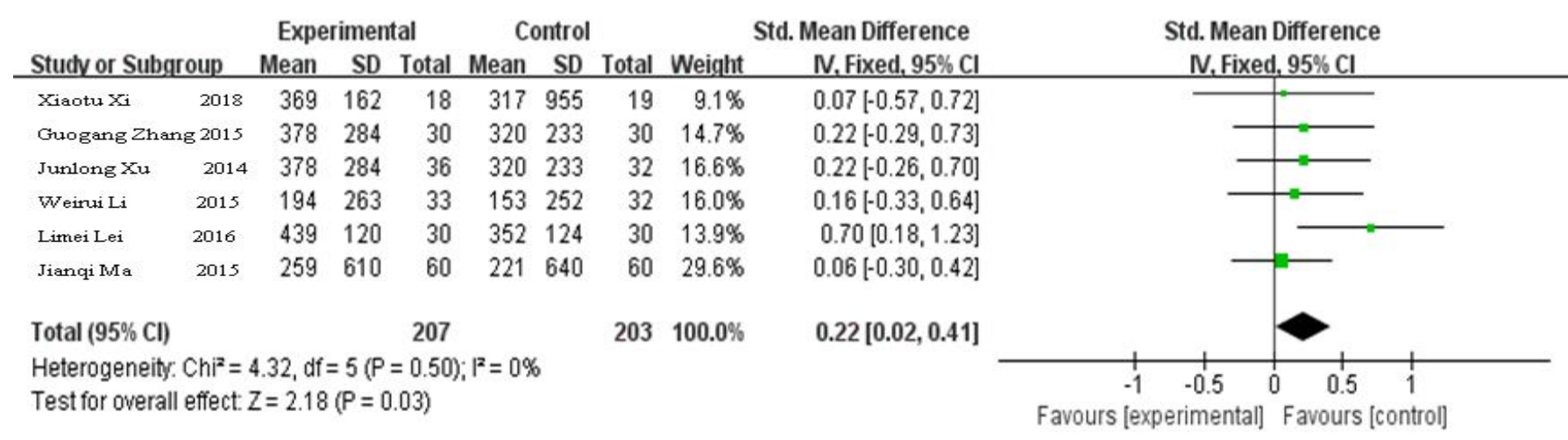

Figure 6. CD4 + forest map

\subsection{CD8+}

Five articles made statistics on the outcome index of CD8 +, which totally was 290 cases, including 147 cases in the experimental group and 143 cases in the control group. Meta-analysis took SMD as the effect quantity, and conducted Q-test on the heterogeneity. It was found that the heterogeneity between the effect quantities $\left(\mathrm{I}^{2}=0 \%, \mathrm{P}=0.41\right)$, indicating that there was no heterogeneity among the studies, so the fixed effect model M-H method was used for analysis. The results of Meta-analysis were the effect value SMD 
$=0.42,95 \% \mathrm{CI}(0.19,0.65) \mathrm{Z}=3.51, \mathrm{P}=0.0004$, that is, there was a difference in CD8 + between the experimental group and the control group, and the difference between the two groups was statistically significant $(\mathrm{P}<0.05)$. As shown in Figure 7:

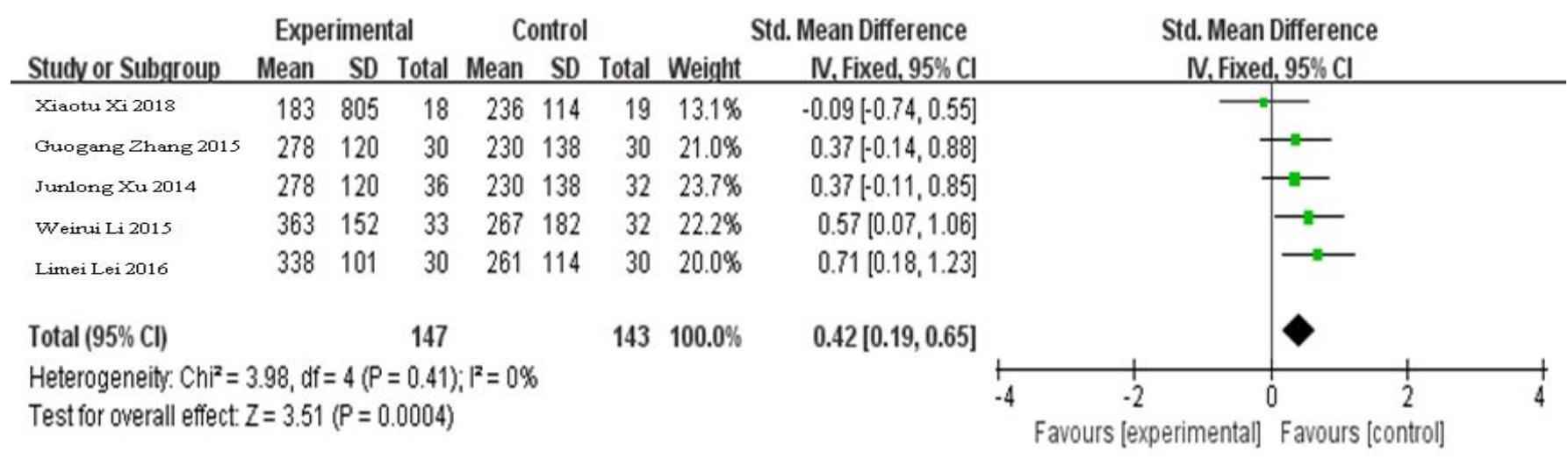

Figure 7. CD8 + forest map

\subsection{CD4+/CD8+}

There were 3 articles on the outcome index of CD4 + / CD8 +, which totally was 180 cases, including 108 cases in the experimental group and 111 cases in the control group. Meta-analysis took SMD as the effect quantity, and conducted Q-test on the heterogeneity. It was found that the heterogeneity between the effect quantities $\left(\mathrm{I}^{2}=24 \%, \mathrm{P}=0.22\right)$, indicating that there was heterogeneity among the studies, but the heterogeneity was small, so fixed-effect model M-H method was used for analysis. The results of Metaanalysis were: The effect value $\mathrm{SMD}=0.17,95 \% \mathrm{CI}(-0.10,0.43) \mathrm{Z}=1.22, \mathrm{P}=0.22$, that is, although there was a difference in CD4 + / CD8 + between the experimental group and the control group, the difference between the two groups was not statistically significant $(\mathrm{P}>0.05)$. As shown in Figure 8:

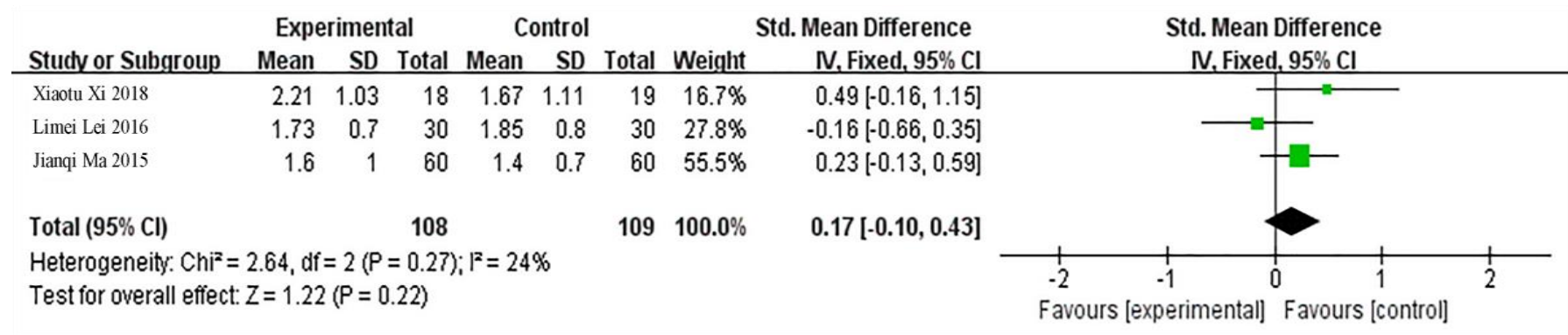

Figure 8. CD4 + / CD8 + forest map

\subsection{NK}

There were 3 articles on NK, which totally was 188 cases, including 96 cases in the experimental group and 92 cases in the control group. Meta-analysis took SMD as the effect quantity, and conducted Q-test on the heterogeneity. It was found that the heterogeneity between the effect quantities (I2 $=24 \%, \mathrm{P}=0.27$ ), indicating that there was heterogeneity among the studies, but the heterogeneity was small, so fixed-effect model M-H method was used for analysis. The results of Meta-analysis were: The effect value $\mathrm{SMD}=0.55$, $95 \% \mathrm{CI}(0.25,0.84) \mathrm{Z}=3.65, \mathrm{P}=0.0003$, that is, although there was a difference in $\mathrm{NK}$ between the experimental group and the control group, the difference between the two groups was statistically significant $(\mathrm{P}<0.05)$. As shown in Figure 9: 


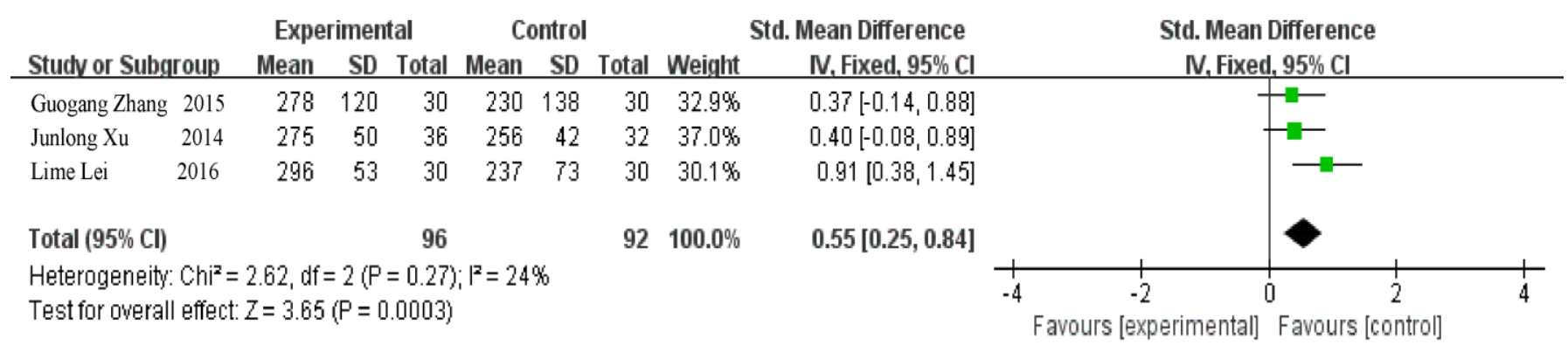

Figure 9. NK forest map

\section{Discussion}

\subsection{Traditional Chinese medicine immune}

Sepsis 3.0 was published in 2016, which emphasizes that it is a life-threatening organ dysfunction caused by the imbalance of host response caused by severe infection. Therefore, regulating this imbalance from the perspective of immunity and inflammation has become a new direction of sepsis treatment ${ }^{[9]}$. The onset of sepsis is due to "positive deficiency for a while, and the Qi outbreak," or the acute attack of feeling lethargic in the chronic deficiency state of old age, long illness and overwork. Acute deficiency syndrome is the core mechanism of sepsis. Deficiency syndrome exists in the whole process of sepsis. Therefore, it is advocated that the treatment method of strengthening the body and strengthening the root runs through the treatment of sepsis, which is similar to the understanding of targeted immune regulation in the treatment of sepsis in modern medicine. Sepsis is caused by pathogenic microorganisms invading the body, and these pathogenic microorganisms belong to external pathogens in traditional Chinese medicine. When the body is attacked by external pathogens, the healthy Qi and pathogenic Qi compete, and the healthy Qi and essence Qi of the human body are consumed and injured, resulting in the deficiency of healthy Qi, and the suppression of immune function caused by sepsis is also closely related to the deficiency of healthy Qi in traditional Chinese Medicine. The changes of $\mathrm{T}$ lymphocyte subsets are closely related to the immune dysfunction of sepsis and are an important index to measure the immunosuppressive state of sepsis ${ }^{[8]}$.

\subsection{Outcome analysis}

In this study, five indexes of $\mathrm{CD} 3+, \mathrm{CD} 4+, \mathrm{CD} 8+, \mathrm{CD} 4+/ \mathrm{CD} 8+$ and $\mathrm{NK}$ cell percentage in patients with sepsis were selected to evaluate the effect of Shenfu Injection on immune function. T lymphocyte subsets can reflect the cellular immune status of the body, in which CD3 + represents the total value of mature T lymphocytes ${ }^{[10]}$; CD4 + can promote the expression of Te and Th, CD $8+$ can promote the expression of Tc and Ts, and CD $4+/$ CD $8+$ can reflect the cellular immune state of the body ${ }^{[11]}$. NK cells play an important role in clearing pathogens. However, the number of NK cells in patients with sepsis decreases. In this case, increasing the number of NK cells and improving the function of NK cells are conducive to infection control ${ }^{[12]}$.

Shenfu Injection originates from Jisheng Prescription written by Yonghe Yan, a famous doctor in Song Dynasty. Ginseng is good at strengthening the vital and tonifying the deficiency; Aconite is good at restoring Yang and rescuing adversity. The whole prescription plays the skills of restoring Yang and rescuing adversity, supplementing Qi and strengthening detachment. According to modern pharmacological, studies, Shenfu injection inhibits endotoxin and inflammatory factors, blocks inflammatory response, and regulates immunologic function dual-directionally, thus promoting body recovery and balancing the Immunosuppressive disorder ${ }^{[13]}$. 


\subsection{Deficiency and Inspiration of this study}

The limitation of this study is that the six literatures included are domestic studies. Although "random grouping" is mentioned, the process of "distribution concealment" is not mentioned. Due to ethics, informed consent and other factors, all studies do not use blind method, the quality of literature is poor, which reduces the accuracy of conclusions. In conclusion, on the basis of routine treatment, the combination of Shenfu Injection can better improve CD4 + level, CD8 + level, NK level, mortality and effective rate, but RCT with multi center, large sample cost and better trial design is still needed to verify the research results.

\section{Disclosure statement}

The authors declare no conflict of interest.

\section{References}

[1] $\mathrm{Hu}$ GY, Hu YK, Hu YR, et al., 2019, Research Progress of Immune Regulation of Traditional Chinese Medicine on Sepsis. Journal of Emergency in Traditional Chinese Medicine, 28(05): 930-933.

[2] Tarsilla M, 2008, Cochrane Handbook for Systematic Reviews of Interventions. Journal of Multidisciplinary Evaluation, 6: 142-148.

[3] Lei LM, Lan X, Kao Y, et al., 2016, Effects of Shenfu Injection on T Cell Subsets, Natural Kller Cells and Prognosis in Patients with Severe Trauma. Chinese Journal of General Practice, 14(05): 743-745.

[4] Ma JQ, Bai JH, Zhu XY, 2015, Clinical Study on Shenfu Injection Combined with Ulinastatin in the Treatment of Sepsis. Drugs \& Clinic, 30(11): 1367-1369.

[5] Xu JL, Zhang N, Zhu HJ, et al., 2014, Effect of Shenfu Injection on Clinical Efficacy and Immune Function in Patients with Severe Sepsis. Zhejiang Medical Journal, 36(06): 471-474.

[6] Li RW, Li XZ, Hao ZW, et al., 2015, Effects of Shenfu Injection Combined with Low Dose Hydrocortisone on Inflammatory Factors and Immune Function in Patients with Severe Sepsis. Journal of Clinical Pulmonary Medicine, 20(07): 1244-1247.

[7] Zhang GG, 2015, Clinical Observation on Shenfu Injection in the Treatment of 30 Patients with Sepsis. Journal of Emergency in Traditional Chinese Medicine, 24(07): 1268-1270.

[8] Xi XT, Zhu MG, Liu YT, et al., 2018, Effect of Shenfu Injection on Immune Function and Inflammation Marks in Patients with Sepsis. Journal of New Chinese Medicine, 50(06): 72-76.

[9] Gentile L, Cuenca A, Efron P, et al., 2012, Persistent Inflammation and Immunosuppression. The Journal of Trauma and Acute Care Surgery, 72: 1491-1501.

[10] Long P, Li X, Jiang LJ, et al., 2017, Clinical Immune Function Analysis of Patients with Septic Shock. Chongqing Medicine, 46(02): 198-200.

[11] Wu TT, Yao YM, 2017, Immune Disorders of Sepsis and Its Clinical Significance. Medical Journal of Chinese People's Liberation Army, 42(02): 95-102.

[12] Bohannon J, Guo Y, Sherwood E, 2012, Toll-Like Receptors Expression and Interferon- $\gamma$ Production by NK Cells in Human Sepsis. Critical Care, London, England, 16: 185.

[13] Guo XQ, Kong L, Fan KL, et al., 2017, Progress in Study of Treating Septic Shock with Shenfu Injection. Journal of New Chinese Medicine, 49(06): 143-145. 